\title{
A Study on the Media Consumers' Behavior Related to Online Communications: Behavioral Economics Perspective
}

\author{
Alice Kyungran $\mathrm{Ma}^{1}$, Takhun Kim${ }^{2}$ and Jongchang Ahn ${ }^{3 *}$ \\ ${ }^{1}$ Department of Media \& Technology Management, University of Cologne \\ Cologne, 50969 - Germany \\ [e-mail: kma1@smail.uni-koeln.de] \\ ${ }^{2}$ School of Management Engineering, KAIST \\ Seoul, 04763 - Republic of Korea \\ [e-mail: thkim1638@gmail.com] \\ ${ }^{3}$ Department of Information Systems, Hanyang University \\ Seoul, 04763 - Republic of Korea \\ [e-mail: ajchang@hanyang.ac.kr] \\ *Corresponding author: Jongchang Ahn
}

Received September 26, 2018; revised March 8, 2019; accepted March 25, 2019;

published May 31, 2019

\begin{abstract}
This research investigates the media consumers' behavior with behavioral economics perspective, especially regarding TV content viewers' behavior; how do online communications influence TV viewers' decision when choosing a new TV content among options. We focus on quantity and attribute of comments or reactions on the online news articles. We analyze that online communications data, which were generated before the first broadcast, affect the TV content consumers' choice for a new TV series. Here we identify a predicted utility, experienced utility and distinction bias in TV media consumption to find the effectiveness of the first viewing choice on whole TV series' episodes. To avoid the crucial influence by exogenous factors, such as season and social issue, the test was done with specific conditions. This research found that the total number

A preliminary version of this paper appeared in 2018 The $13^{\text {th }}$ Asia Pacific International Conference on Information Science and Technology (APIC-IST 2018), June 24-27, Nha Trang, Vietnam. This version includes a concrete analysis and significant result. "This research was supported by Basic Science Research Program through the National Research Foundation of Korea(NRF) funded by the Ministry of Education(2017R1D1A1B03031824).“
\end{abstract}


of reactions to the comments by itself positively affects the audiences' decision-making behavior for a new TV content choice. This influence was regardless of favor/ non-flavor reactions. This study contributes to the literature on media economics and management by exploring the media content users' consuming behavior and making a first step for finding an important influencer on the media content consumption.

Keywords: Online communications, comments and reactions, media consumers, willingness to watch, distinction bias, behavioral economics

\section{Introduction}

Decision making on selecting a new TV series is related to the research on media consumers' behavior. What does affect the choice of media content? What information do media consumers need to predict the quality of media content for a choice of new TV series on a streaming terrestrial service? Being different from other video content, for viewing the streaming TV content, media consumers choose the one content among competitive options. Since selecting and watching the first episode of a new TV series, they may keep their first choice, or they may change their choice to other optional content. What experiential difference affects the media consumers' behavior? We investigated the media consumers' behavior on a new TV series viewing pattern with behavioral economics theories, such as the anchoring effect and the distinction bias perspective with online communication data.

For making a decision on the judgment or predicting something that is uncertain, people tend to maintain the anchoring and adjustment heuristic process and finally reach the prediction value. The heuristic maintains that anchoring bias is caused by insufficient adjustment because final judgments are assimilated toward the starting point of a judge's deliberations [1]. The literature indicates that, in decision making, the higher the ambiguity, the lower the familiarity, relevance or personal involvement with the problem; a more trustworthy source or plausible bid/estimate, the stronger the anchoring effect [2]. Since media products such as TV content are relevant to this type, it is very difficult to predict the degree of entertainment and the quality of the content itself, because media is an area of information and creativity. Note that the term "TV content" is defined broadly in this study, which includes the program content itself [3].

Because media product, including TV content, is considered experiential goods, it is very hard to predict the quality and value of the new content. If new, alternative TV series are broadcasted at the same scheduling time, which content will be selected? This selection is often not easy for content consumers, practice managers and researchers. How is the decision of content choice to be made among competitive media contents? 
To predict the value of a new TV series content, in other words, to choose what to watch in prime time, viewers try to obtain some information. The audience and web users will likely expect to obtain gratification from internet-enhanced news and another programming-related content from a station website [4]. Individuals use various media devices to search for additional information [5], visit a website mentioned in the program, or check fact information about a show [6]. In addition to reading online entertainment news articles, viewers check the number and context of comment, reply and reaction (good or bad) regarding the actors, genre, script, and producers.

At this moment, do these numbers of comments and reactions play the role as the initially presented value of the anchoring effect theory [1] and affect the viewers' decision-making process to consume the TV content? Do other factors which affect the TV content choice exist? This research aims to make the first step to apply the anchoring effect to TV content consumption empirically, building on the following research question: What affects the audience's willingness to watch TV content?

The anchoring effect is one of the most robust cognitive heuristics. Previous literature [7] has examined many different domains and tasks in all decision-making processes. The examples of domains are general knowledge, probability estimate, legal judgment, valuation/purchasing decision, and forecasting, and these are studied with material goods having characteristics of excludability, expendability, and rivalry and their market [7].

Being different from material goods, TV content as one of the most important media products is goods with the attributes of non-excludability, non-expendability, and the interdependence of utility and powerful social effect. Media economy is the 'attention economy' [8]. Anyone who is unwilling to pay for TV content can access the broadcasting service with bundling commercial advertisement. This is not the case for Adam Smith's invisible hand which applies to the material goods.

Broadcasting business is the selling of audiences to advertisers - the larger the audience, the higher the commercial rates. The broadcaster has to capture their audience as long as possible and as many as possible (higher TV ratings) for advertisement sales revenue. In the case of TV series content, the ratings and evaluation of the first episode are crucially important. From a research perspective of the anchoring effect theory, this study investigates if the behavior of acquiring and sharing information about the new content before broadcasting can influence the viewers' willingness to watch.

When people experience (view) the first episode of what they chose, they may compare their experienced satisfaction with predicted satisfaction with the content. If the gap between prediction utility and experience utility is same or positively significant, it leads the media consumers to keep viewing. On the contrary to this, the significant negative gap makes them change the content for the next viewing. Here we have another research aim to apply the distinction (misprediction) bias to TV content consumption empirically, building on the following research question: What affects the media consumers' content choice behavior? In detail, how does the utility difference affect the media consumers' content choice behavior? 
This paper analyzed the correlation between the quantity of comments and reactions and TV ratings. The data of comments and reactions on the online news are acquired from web crawler (bot) software; the TV ratings are gathered from the Nielsen Company (www.nielsen.com).

The remainder of this paper is organized as follows: Section 2 reviews the relevant literature. Section 3 outlines the research design and Section 4 describes the method used for data collection and empirical analysis. Analytical results are reported in Section 5. Section 6 discusses and concludes the proposed research, including further research and limitations.

\section{Literature Review}

\subsection{Media Management and Economics}

The scholars who studied theoretical tradition sphere have tried to explain choices, decisions and other economic factors affecting producers and consumers of communications goods and services and have designed support forecasts for the prospects and effects of the development of media $[9,10,11]$. The applied tradition emerged from business, economics, and management departments have often explored the structure of communication industries and their markets, with an emphasis on understanding trends and changes responding to the fluctuations in the economy and consumer behavior [12].

As time progressed, the issue of the appearance of new media became more significant. A great deal of change in communications has resulted in changing technologies and questions raised about those changes [12]. Technological change is an inevitable and underlying force of progress in media industries. Volume and velocity of those changes pose a great challenge to all media sectors [13]. Technological development and innovation lead the media to one of a handful of industries.

The radio industry survived with a unique type of media in spite of the emergence of TV. Similarly, TV watching patterns will exist as an important viewing behavior in a very competitive era with digitalized products, multi-platforms, multi-devices and multi-channel. Instead, today TV audiences are experiencing greater control over how they consume TV in the platforms that best suit their needs. Increasing numbers of TV viewers with internet access are tele-webbing or surfing the web while watching TV [14]. Social TV viewing is emerging as a noteworthy phenomenon - the act of social media while watching TV [15]. Watching TV content and communicating with other audiences often simultaneously happen in online space.

\subsection{Social Engagement among TV Content Users}

Social engagement refers to the degree of interactions or connections that a viewer develops with TV content through various social media [3]. It has been suggested that engagement is primarily driven by program content in the TV consumption context, and the deepest engagement experience happens at the content level [16]. 
The combination of TV and social media is developing a new killer application in the digitalized media era. This combination allows simultaneous viewing desire (to see live broadcasting) and communication desire (to express various opinions on the desired TV shows) (www.tvnewscheck.com), meaning that viewers' communication desire for TV shows is strong. As a tool for measuring viewers' behavioral patterns in social media, social impression (calculated by measuring conversation volume, page views, number of visitors, and attributes of the people who write comments, reply, or debate each other in social media) will play an important role in determining the flow of money [17]. The information generated as a result of user interactions on social networking sites influences the decision-making process of consumers [18].

The marriage between traditional TV and the emerging social media can be attributed to the growing adoption of social media tools by consumers and their increasing cross-platform and multitasking pattern [5]. Viewer engagement is "a more passion-driven and more socially driven mode of watching TV" across as many platforms as possible [19].

While past research focused on the phenomenon of social engagement during the TV shows' broadcasting period, this study aims to explore the implication with the data created during three (3) weeks in advance from the first broadcast. Normally TV stations promoted new content through public relations (PR) for three (3) weeks before it is first aired. This promotion strategy in the broadcasting industry is considered a comprehensive concept of serial activities [20], which undertaken to provoke viewers' viewing behavior [21]. The forms of those data are comments on online news articles concerned with the new content, and reaction (good/bad or favor/ non-favor) to the comments.

\subsection{Anchoring effect}

Heuristics are characterized as an 'intuitive, rapid, and automatic system' [22], which 'reduce the complex tasks of assessing probabilities and predicting values to simpler judgmental operations.' Although the use of rules of thumb reduces cognitive and time constraints, sometimes they lead to severe and systematic errors such as biases and fallacies in decision making [1]. One of the representative heuristics is anchoring heuristic, which is a ubiquitous phenomenon in human judgment.

The anchoring-and-adjustment heuristics [1], first introduced by Tversky and Kahneman in their pioneering work on judgment under uncertainty, could be the main anchoring effect referred to in the current study. The heuristic maintains that anchoring bias is caused by insufficient adjustment because final judgments are assimilated toward the starting point of a judge's deliberations. The anchoring effect is the disproportionate influence on decision makers to make judgments that are biased toward an initially presented value [1]. Following their study, many studies have illustrated the prevalence of anchoring effect in human decision-making processes. For TV content, valuations/purchasing decisions [23] and forecasting [24,25] among domains, attitude change among perspectives [26,27,28], and knowledge/experience/expertise among human factors $[24,29,30]$ are available to TV media content. 
As previously written, in decision making, the higher the ambiguity, the lower the familiarity, relevance or personal involvement with the problem; a more trustworthy source or plausible bid/estimate, the stronger the anchoring effects [2]. Estimates are biased toward the anchor values. Strack and Mussweiler explained, "Anchor values serve as the reference point for people to adjust the boundary of the range of plausible values for the question, presuming that the given anchor is more extreme than the boundary value for the range of plausible answers [30,31]."

Here we can assume that if the viewer sees the extremely high number of comments about the new TV content, the influence on the judgment of content choice and the content evaluation could also be high. This research assumes that the number of comments and reactions generated before broadcasting is considered as an initially presented value for forecasting and decision making to select TV content, whereas the ratings reflect the TV content consumers' behavior pattern.

\subsection{Distinction bias}

Traditional decision theorists assume that when choosing between options that have the same costs, decision makers analyze which option will deliver the highest expected outcome utility and choose that option. This is a consequentiality utility analysis approach. Behavioral decision theorists have proposed that decision makers' effect often drives choices toward the choice options [32-38](e.g. Frederick, 2002; Hsee \& Rottenstreich, 2002; Kahneman, Schkade, \& Sunstein, 1998; Loewenstein, 1996; Loewenstein et al., 2001; Rottenstreich \& Hsee, 2001; Slovic et al., 2002). Media product, including TV content, is considered experiential goods. It is hard to predict the quality and value of the new content, especially alternative optional TV series broadcast at the same scheduling time. These characteristics lead media consumers to have an affect heuristic-driven decision-making process than the consequentiality utility analysis.

In a series of seminal articles, Kahneman and his co-authors have argued that what people predict will make them happy (i.e., predicted utility) and what people choose (i.e., decision utility) can be systematically different from what actually makes them happy (i.e., experienced utility) [39-42]. In other words, people may mispredict and mischoose. When people make choices with uncertainty, they are often in the joint evaluation (JE) mode; when people experience an event, they are often in the single evaluation (SE) mode [43].

In this similar case, when people decide which content to choose for TV streaming viewing, they often predict the level of future viewing satisfaction. When people view (experience) the first episode of what we choose, they often compare their experienced satisfaction with predicted satisfaction with the content. The utility difference between the heuristic judgment (the predicted utility generated by online news article and comments before broadcasting) and the experienced utility (obtained by TV viewing) is our research topic. 


\section{Research Design}

\subsection{Conceptual Framework}

Fig. 1 presents a formal model to explore the process of audiences' decision making for the choice of new TV content correlated with the information of online data value. In addition, Fig. 2 presents the model to demonstrate how anchoring effect influences on audiences' willingness to watch TV content (consumers' behavior) under the anchoring-and-adjustment mechanism. The number of comments and reactions on the online news is considered as the initially presented value of the anchoring effect. This study can be also considered as an exploratory research by analyzing TV rating data gathered from the Nielsen (www.nielsen.com) combined with buzz data like comments and reactions on online news articles. These buzz data were collected from a major Korean portal site using the crawling software.

\begin{tabular}{|c|c|c|c|c|}
\hline $\begin{array}{c}\text { Step } 1 . \\
\text { Getting information } \\
\text { via the online news } \\
\text { article }\end{array}$ & $\Rightarrow$ & $\begin{array}{c}\text { Step } 2 . \\
\text { Checking other viewers' } \\
\text { comments and reactions } \\
\text { (favor/ non-favor) }\end{array}$ & $\Rightarrow$ & $\begin{array}{c}\text { Step } 3 . \\
\text { Making a decision; what to } \\
\text { choose for a new TV content } \\
\text { (Media consumers' behavior) }\end{array}$ \\
\hline
\end{tabular}

Fig. 1. The normal process of audiences' decision making for a new TV content by online communication data

\begin{tabular}{|c|}
\hline Anchoring effect \\
\hline $\begin{array}{c}\text { Reading consumers' online communication data to online articles about a new content } \\
- \text { - Number of comments } \\
\text { - Number of Reactions (favor/non-favor) }\end{array}$ \\
\hline$\sqrt{2}$ \\
\hline Prediction \\
\hline $\begin{array}{l}\text { Predicting the value of a new content } \\
\text { - affected by other consumers' comments context and the number }\end{array}$ \\
\hline$\sqrt{3}$ \\
\hline Decision (choice) \\
\hline $\begin{array}{l}\text { Making a judgment to choose a new content for the first watching selection } \\
\text { - This affects the willingness to watch (WTW) }\end{array}$ \\
\hline$\sqrt{3}$ \\
\hline Consumers' behavior for the first episode \\
\hline $\begin{array}{l}\text { Watching the content that was decided by the process of media viewing behavior } \\
\text { - TV ratings reflect the consumers' viewing behavior }\end{array}$ \\
\hline
\end{tabular}




\begin{tabular}{|c|}
\hline Distinctive bias \\
\hline $\begin{array}{r}\text { Comparing the experienced satisfaction with predicted satisfaction after v } \\
\text { - evaluation of predicted utility/ experienced utility }\end{array}$ \\
\hline b \\
\hline Consumers' behavior for next other episodes \\
\hline $\begin{array}{c}\text { Prediction utility } \geq \text { experience utility } \\
\text {; stop/ keep viewing/change their viewing content } \\
\text { Prediction utility }<\text { experience utility } \\
\text {; keep viewing }\end{array}$ \\
\hline
\end{tabular}

Fig. 2. The process of viewing behavior from the perspective of behavioral economics

In this paper, the concrete definitions of key terms need to be described:

- TV ratings represent the viewing rate for TV content. All ratings data were gathered from Nielsen and measured in ATS (=EA/Reach) where ATS means an average of the audience expressed in minutes; EA means estimated audience; and Reach means scope. TV ratings reflect the percentage of the total population of TV tuned to a particular program (Nielsen).

- The comment is the text written in some article to express the reader's opinion, including positive and negative comments.

- The reaction (favor/non-favor or like/dislike) is directly combined with the comment of online news articles. The online users leave their feeling by clicking the favor or non-favor button after reading the news and comments

\subsection{Research Hypotheses}

On the online articles, there are various types of number data information generated by media users, such as the number of comments, the number of favor reactions, and the number of non-favor reactions, time generated by online users, the ranking of the largest comments, and so on. We focused on the three (3) data types as factors to influence media consumers' viewing behavior to select new TV content. We can see the number of these kinds of data beside the title of the article or below the article and someplace near the article. The first type is the amount of comments. It shows the degree of attention or interest in new TV content. The other two types of numbers show the atmosphere of media users' opinion; one is the amount of favor reaction to a comment, and the other is the amount of non-favor reaction to a comment.

We offer exploratory hypotheses that resonate with the proposed theoretical approach from the basic research question (What affects the audience's willingness to watch TV content?). As mentioned above, this paper investigates two themes. Firstly, how does the anchoring effect influence audiences' willingness to watch TV content (consumers' behavior) with the data of comments and reactions as an initially presented value? 
Secondly, we investigate how long anchoring effect influences on whole episodes. This aims to discover how the utility difference affects the media consumers' content choice behavior. The utility difference is the gap between the heuristic judgment (predicted utility) by online data (news article and comments) before broadcast and the experienced utility obtained after TV viewing. The data of comments and reactions were generated three months before the first episode 's broadcast. This purpose leads to the following hypothesis.

H1: The number of comments and reactions positively affects the audiences' decision making of the willingness to watch (WTW) for the first episode.

H1-1: The total number of comments (positive and negative) positively affects the audiences' decision making of the WTW for the first episode.

H1-2: The total number of comments with regard to the attribute of comments and reactions (favor or non-favor) positively affects the audiences’ decision making of the WTW for the first episode.

H1-3 The total number of reactions (favor/non-favor or like/dislike) positively affects the audiences' decision-making of the WTW for the first episode.

H1-4: The total number of comments with regard to the amount of reactions (favor and non-favor) positively affects the audiences' decision making of the WTW for the first episode.

H2: The number of comments and reactions positively affects the audiences' decision making of the WTW from the second episode.

H2-1 The total number of comments (positive and negative) positively affects the audiences' decision making of the WTW from the second episode.

H2-2 The total number of comments with regard to the attribute of comments and reactions (favor or non-favor) positively affects the audiences' decision making of the WTW from the second episode.

H2-3 The total number of reactions (favor/non-favor or like/dislike) positively affects the audiences' decision-making of the WTW from the second episode

H2-4 The total number of comments with regard to the amount of reactions (favor and non-favor) positively affects the audiences' decision making of the WTW from the second episode.

\section{Method}

\subsection{Data Collection}

The main online data source of comments and reactions is from a website, which is an internet content service operator with a searching portal in oligopolistic position in South Korea. With ten (10) titles of TV series, 69,033 comments, and 3,466,852 reactions by the 
process of web crawling and filtering with programming language $\mathrm{R}$ were collected. The text mining of comments was manually done for the accurate analysis of the complex and ambiguous expression in comments. As mentioned previously, TV ratings represent the viewing rate for TV content. All ratings data were gathered from the Nielsen Korea (www.nielsenkorea.co.kr). To avoid the crucial influence by external factors, such as season and social issue, the test was done with conditions; Ten (10) titles of TV series which have same genre (drama), similar core audience targeting (20-49's women), similar broadcasting period (June - October of 2016), same scheduling (22:00-23:00 on weekdays) and aired on terrestrial TV platform like Table 1.

Table 1. The titles of tested TV series

\begin{tabular}{|c|c|c|c|}
\hline Title & $\begin{array}{c}\text { Three weeks period } \\
\text { for online data }\end{array}$ & $\begin{array}{c}\text { Genre } \\
\text { (drama) }\end{array}$ & $\begin{array}{c}\text { TV Platform/ } \\
\text { Channel } \\
\text { (in Korea) }\end{array}$ \\
\hline Doctors (DO) & $31.05-20.06$ & Medical romance & Terrestrial (SBS) \\
\hline Beautiful Mind (BM) & $31.05-20.06$ & Medical & Terrestrial (KBS) \\
\hline $\begin{array}{c}\text { Uncontrollably Fond } \\
\text { (UF) }\end{array}$ & $16.06-06.07$ & Romance & Terrestrial (KBS) \\
\hline W (W) & $30.06-20.07$ & Fantasy & Terrestrial (MBC) \\
\hline God of Jealousy (GJ) & $03.08-24.08$ & Romantic comedy & Terrestrial (SBS) \\
\hline $\begin{array}{c}\text { Love in Moonlight } \\
\text { (LM) }\end{array}$ & $01.08-22.08$ & Historical romance & Terrestrial (KBS) \\
\hline $\begin{array}{c}\text { A Couple of Moon } \\
\text { (CM) }\end{array}$ & $08.08-29.08$ & Historical & Terrestrial (SBS) \\
\hline $\begin{array}{c}\text { Way to Airport (WA) } \\
\text { King of Shopping } \\
\text { (KS) }\end{array}$ & $31.08-21.09$ & Romance & Terrestrial (KBS) \\
\hline $\begin{array}{c}\text { Carrying Woman } \\
\text { (CW) }\end{array}$ & $05.09-26.09$ & Detective & Terrestrial (MBC) \\
\hline
\end{tabular}

[Abbreviation] Doctors: DO, Beautiful Mind: BM, Uncontrollably Fond: UF, W: W, God of Jealousy: GJ, Love in Moonlight: LM, A Couple of Moon: CM, Way to Airport: WA, King of Shopping: KS, Carrying Woman: CW; These abbreviations were equally applied to Table 2 and Table 3.

\subsection{Operationalization and Measurement of Variables}

The model for assessing the hypotheses comprises two independent variables of the total number of comments, and two adjusted number of comments with reactions, and one dependent variable, TV ratings. 


\subsubsection{Independent variables}

We investigated four different independent variables to show how many interest do TV dr ama viewers have in advance; the total number of comments, the total number of commen ts reflecting the attribute and reactions (favor/non-favor), the total number of reactions, an $\mathrm{d}$ the total number of comments with regard to the amount of reactions. All independent $\mathrm{v}$ ariables were generated three weeks before the first broadcast. Table 2 presents data of in dependent variables.

$\mathrm{X}_{1}$ : The total number of comments regardless of the attribute (positive or negative)

$\mathrm{X}_{2}$ : The total number of comments reflecting the attribute of comments and reactions (fav or or non-favor)

$\mathrm{X}_{3}$ : The total number of reactions (favor and non-favor) to the comments on articles

$\mathrm{X}_{4}$ : The total number of comments with regard to the amount of reactions

$i$ : The order of comment on news articles (e.g., the $i$ th comment on news articles)

$\beta:+1$ (if the comment is favor), -1 (if the comment is non-favor)

$a_{i}$ : The number of favor reactions on the $i$ th comment

$b_{i}$ : The number of non-favor reactions on the $i t h$ comment

$\mathrm{x}_{i}$ : The value of $i$ th comment (every $\mathrm{x}_{i}=1$ )

$$
\begin{array}{ll}
\text { (1) } \mathrm{X}_{1}=\sum_{i=1}^{n}|\beta| \mathrm{x}_{i} & \text { (2) } \mathrm{X}_{2}=\sum_{i=1}^{n} \beta \mathrm{x}_{i}\left(a_{i}-b_{i}\right) \\
\text { (3) } \mathrm{X}_{3}=\sum_{i=1}^{n}\left(a_{i}+b_{i}\right) & \text { (4) } \mathrm{X}_{4}=\frac{\sum_{i=1}^{n} \beta \mathrm{x}_{i}\left(a_{i}-b_{i}\right)}{\sum_{i=1}^{n}\left(a_{i}+b_{i}\right)}
\end{array}
$$

(1) $X_{1}$ means how much the content has interest by the media consumers, and (2) $X_{2}$ indicates the general opinion about the new media content. (3) $X_{3}$ is the independent variable with the clicking action as media consumers' simple type of participation, which can be the maximum index of interest degree. (4) $\mathrm{X}_{4}$ is the index which shows the degree of interest among potential reliable viewers.

\subsubsection{Dependent Variable}

TV ratings as a dependent variable represent the viewing rate for TV content. All ratings data were gathered from the Nielsen Korea (www.nielsenkorea.co.kr). Table 3 presents th e data of each episode's viewing rate of dependent variable.

$Y j=\mathrm{TV}$ ratings of $j$ th episode of TV series drama $(j=1,2,3 \ldots 24)$

Table 2. Data of variables (Individual criteria)

\begin{tabular}{|c|r|r|r|r|r|}
\hline Title & \multicolumn{1}{|c|}{$\mathrm{X}_{1}$} & \multicolumn{1}{|c|}{$\mathrm{X}_{2}$} & \multicolumn{1}{c|}{$\mathrm{X}_{3}$} & \multicolumn{1}{c|}{$\mathrm{X}_{4}$} & $\mathrm{Y}_{1}$ \\
\hline DO & 6,067 & 162,027 & 325,852 & 0.497 & 5.083 \\
\hline BM & 2,202 & 7,503 & 82,013 & 0.091 & 5.617 \\
\hline UF & 13,031 & 176,782 & 662,555 & 0.267 & 4.327 \\
\hline W & 6,877 & 93,702 & 391,932 & 0.239 & 5.922 \\
\hline GJ & 2,911 & 41,707 & 140,796 & 0.296 & 3.980 \\
\hline LM & 17,390 & 489,449 & 861,975 & 0.568 & 8.937 \\
\hline
\end{tabular}




\begin{tabular}{|c|r|r|r|r|r|}
\hline CM & 12,886 & 2,598 & 671,455 & 0.004 & 1.991 \\
\hline WA & 3,084 & $-15,481$ & 129,025 & -0.120 & 3.077 \\
\hline KS & 2,932 & 85,058 & 137,623 & 0.618 & 2.428 \\
\hline CW & 1,653 & 27,816 & 63,626 & 0.437 & 2.546 \\
\hline
\end{tabular}

Table 3. Dependent variables of each episode (Household criteria)

\begin{tabular}{|c|c|c|c|c|c|c|c|c|c|c|c|c|}
\hline Title & $Y_{1}$ & $\mathbf{Y}_{2}$ & $\mathbf{Y}_{3}$ & $\mathbf{Y}_{4}$ & $\mathbf{Y}_{5}$ & $\mathbf{Y}_{6}$ & $\mathbf{Y}_{7}$ & $\mathbf{Y}_{8}$ & $Y_{9}$ & $\mathbf{Y}_{10}$ & $\mathbf{Y}_{11}$ & $\mathbf{Y}_{12}$ \\
\hline $\mathrm{DO}$ & 12.9 & 14.2 & 14.4 & 15.6 & 18.4 & 19.7 & 18.8 & 19.2 & 19.4 & 19.3 & 19.2 & 18.7 \\
\hline $\mathrm{BM}$ & 4.1 & 4.5 & 4.8 & 4.5 & 3.5 & 4.0 & 3.5 & 3.5 & 4.4 & 3.9 & 3.4 & 3.9 \\
\hline UF & 12.5 & 12.5 & 11.9 & 11.0 & 12.9 & 11.1 & 8.6 & 8.9 & 8.2 & 8.1 & 7.9 & 9.9 \\
\hline $\mathrm{W}$ & 8.6 & 9.5 & 12.9 & 12.9 & 13.5 & 12.2 & 13.8 & 12.2 & 11.3 & 12.3 & 12.2 & 11.1 \\
\hline GJ & 7.3 & 8.3 & 8.7 & 9.1 & 9.9 & 9.1 & 8.1 & 10.1 & 12.3 & 13.2 & 12.1 & 12.3 \\
\hline LM & 8.3 & 8.5 & 16.0 & 16.4 & 19.3 & 18.8 & 20.4 & 19.7 & 21.3 & 19.6 & 20.7 & 20.1 \\
\hline $\mathrm{CM}$ & 7.4 & 9.3 & 7.0 & 5.7 & 6.0 & 5.7 & 5.8 & 6.9 & 6.2 & 7.1 & 7.5 & 7.9 \\
\hline WA & 7.4 & 7.5 & 9 & 8.3 & 7.5 & 9.1 & 8.5 & 7.4 & 7.8 & 8.1 & 8.8 & 9.3 \\
\hline KS & 5.6 & 6.2 & 7.0 & 7.8 & 8.4 & 8.8 & 10.0 & 9.7 & 10.7 & 10.2 & 10.5 & 11.0 \\
\hline CW & 6.9 & 8.4 & 7.9 & 8.6 & 8.2 & 9.6 & 8.2 & 7.9 & 8.3 & 7.1 & 8.1 & 8.2 \\
\hline Title & $Y_{13}$ & $Y_{14}$ & $\mathbf{Y}_{15}$ & $Y_{16}$ & $\mathbf{Y}_{17}$ & $\mathbf{Y}_{18}$ & $Y_{19}$ & $\mathbf{Y}_{20}$ & $\mathbf{Y}_{21}$ & $\mathbf{Y}_{22}$ & $\mathbf{Y}_{23}$ & $\mathbf{Y}_{24}$ \\
\hline $\mathrm{DO}$ & 18.5 & 19.6 & 21.3 & 20.6 & 20.8 & 17.8 & 19.5 & 20.2 & - & 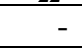 & - & - \\
\hline BM & 2.8 & 3.2 & - & - & - & - & - & - & - & - & - & - \\
\hline UF & 8.0 & 8.7 & 8.0 & 7.7 & 8.0 & 7.9 & 8.0 & 8.4 & - & 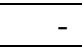 & - & - \\
\hline $\mathrm{W}$ & 11.9 & 10.9 & 11.4 & 9.3 & - & - & 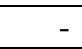 & - & - & 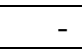 & - & - \\
\hline GJ & 11.9 & 12.6 & 11.2 & 11.7 & 11.8 & 11.8 & 10.2 & 10.2 & 9.7 & 10.6 & 9.4 & 11.0 \\
\hline LM & 18.5 & 18.7 & 17.9 & 18.8 & 23.3 & 22.9 & - & - & - & - & - & - \\
\hline CM & 8.2 & 6.8 & 8.2 & 5.9 & 9.8 & 10.1 & 9.0 & 11.3 & - & - & - & - \\
\hline WA & 8.5 & 9.1 & 8.1 & 8.4 & - & - & - & - & - & - & - & - \\
\hline KS & 10.0 & 10.4 & 9.7 & 8.9 & - & - & - & - & - & - & - & - \\
\hline CW & 9.1 & 8.9 & 8.9 & 10 & - & - & - & - & - & - & - & \\
\hline
\end{tabular}

\section{Results}

\subsection{Regression Analysis (1)}

The reliability of measured items was tested as a consistency index. In the case of having many variations among variables, Cronbach's Alpha value based on standardized items was recommended and used. The value is 0.825 , so the measured items are considered reliable. Scales with reliabilities of 0.7 or greater are recommended in social science research [44]. This research begins with this hypothesis: The number of comments and reaction (initially presented value $=$ anchor) positively affects the audiences' willingness to watch TV. From the differential degree of reaction reflection, there are four independent variables, which are $\mathrm{X}_{1}$ (the total number of comments), $\mathrm{X}_{2}$ (the total number of comments with regard to the attitude of reaction), $X_{3}$ (the total number of reactions for favor and non-favor), and $\mathrm{X}_{4}$ (The total number of comments with regard to the amount of reactions). The stepwise regression is a method for dividing effective and ineffective variables based 
on the significance of each partial regression coefficient. Only $\mathrm{X}_{3}$ variable significantly explains TV ratings as a dependent variable (the revised $R^{2}$ value is 0.550 ). Thus, H1-3 (The total number of reactions with favor/ non-favor positively affects the audiences' decision making of the WTW for the first episode) was accepted. The F-value (12.014) was presented significantly under p-value (0.008) at a 0.01 level and presented a significant regression equation. The standardized beta coefficient value was 0.775 and t-value 3.466.

To check the concern of the potential existence of a multi-collinearity problem, we examined it formally by using variance inflation factor (VIF), which indicates the degree to which each predictor variable is explained by predicted variables, is a common measure of the multi-collinearity in regression analysis. In this study, the multi-collinearity problem is not in question because VIF presented 1 in the recommended criteria below 10 [45,46], and a tolerance presented 1 in the recommended criteria over 0.1. The Durbin-Watson value is 2.201 in the recommended criteria near 2.0, which presented no correlation among residuals.

\subsection{Regression Analysis (2)}

This research begins with this hypothesis: The number of comments and reaction (initially presented value $=$ anchor) positively affects the audiences' WTW TV. Table 4 presented that $\mathrm{X}_{3}$ significantly explained the first and the second episodes' TV ratings as a dependent variable. It is the independent variable with the clicking action as media consumers' simple participation and shows the maximum index of interest degree. Thus, H2-3 (The total number of reactions (favor/non-favor or like/dislike) positively affects the audiences' decision-making of the WTW from the second episode) was accepted. $\mathrm{X}_{2}$ explained from the 3rd to the $14^{\text {th }}$, and $16^{\text {th }}$ episodes' ratings seriously, which indicates the general opinion (quantity and attribute) about the new TV series. Thus, H1-2 (The total number of comments with regard to the attribute of comments and reactions (favor or non-favor) positively affects the audiences' decision making of the WTW from the second episode) was accepted.

Table 4. The result of stepwise regression analysis to each $n$th episode

\begin{tabular}{|c|c|c|c|}
\hline \multirow{2}{*}{$\begin{array}{c}\text { Ratings of } \\
\text { nth episode: } \\
\text { Yn }(\mathrm{n}=1 \ldots \\
24)\end{array}$} & \multicolumn{2}{|c|}{$\begin{array}{l}\text { Variables which significantly explained TV ratings } \\
\text { as a dependent variable under Stepwise Regression }\end{array}$} & \multirow{2}{*}{ Summary } \\
\hline & $95 \%$ & $99 \%$ & \\
\hline $\mathrm{Y}_{1}$ & & $\mathrm{X}_{3}(\mathrm{p}=0.008)$ & \multirow{2}{*}{$\begin{array}{c}\mathrm{X}_{3} \text { significantly explained } \\
\text { TV ratings. }\end{array}$} \\
\hline $\mathrm{Y}_{2}$ & $\mathrm{X}_{3}(\mathrm{p}=0.014)$ & & \\
\hline $\mathrm{Y}_{3}$ & & $\mathrm{X}_{2}(\mathrm{p}=0.003)$ & \multirow{7}{*}{$\begin{array}{c}\mathrm{X}_{2} \text { significantly } \\
\text { explained TV ratings. } \\
\text { ( } \mathrm{X}_{2:} \text { the total number of } \\
\text { comments with regard to } \\
\text { the attitude of reaction) }\end{array}$} \\
\hline$Y_{4}$ & & $\mathrm{X}_{2}(\mathrm{p}=0.003)$ & \\
\hline $\mathrm{Y}_{5}$ & & $\mathrm{X}_{2}(\mathrm{p}=0.004)$ & \\
\hline $\mathrm{Y}_{6}$ & & $\mathrm{X}_{2}(\mathrm{p}=0.004)$ & \\
\hline $\mathrm{Y}_{7}$ & & $\mathrm{X}_{2}(\mathrm{p}=0.005)$ & \\
\hline $\mathrm{Y}_{8}$ & & $\mathrm{X}_{2}(\mathrm{p}=0.007)$ & \\
\hline$Y_{9}$ & & $\mathrm{X}_{2}(\mathrm{p}=0.008)$ & \\
\hline
\end{tabular}




\begin{tabular}{|c|c|c|c|}
\hline $\mathrm{Y}_{10}$ & $\mathrm{X}_{2}(\mathrm{p}=0.014)$ & & \multirow{2}{*}{} \\
\hline $\mathrm{Y}_{11}$ & $\mathrm{X}_{2}(\mathrm{p}=0.018)$ & & \\
\hline $\mathrm{Y}_{12}$ & & $\mathrm{X}_{2}(\mathrm{p}=0.007)$ & \\
\hline $\mathrm{Y}_{13}$ & $\mathrm{X}_{2}(\mathrm{p}=0.016)$ & & \\
\hline $\mathrm{Y}_{14}$ & $\mathrm{X}_{2}(\mathrm{p}=0.026)$ & & - \\
\hline $\mathrm{Y}_{15}$ & - & - & $\mathrm{X}_{2}$ is significant. \\
\hline $\mathrm{Y}_{16}$ & $\mathrm{X}_{2}(\mathrm{p}=0.041)$ & - & - \\
\hline $\mathrm{Y}_{17}$ & - & - & - \\
\hline $\mathrm{Y}_{18}$ & - & - & - \\
\hline $\mathrm{Y}_{19}-\mathrm{Y}_{24}$ & - & - & \\
\hline
\end{tabular}

\section{Conclusion}

Based on the empirical analysis, we can conclude that the total amount of reactions to the comments (initially presented value) which media consumers generated in advance before broadcasting positively influences the decision making to new TV content choice. People's heuristic judgment system seems to influence the consumption behavior of media content in a very short time. To sum up, the anchoring effect appears in TV content viewing consumption through the communication behavior on online space, and we can perceive the degree of interest in a new TV content by the number of reactions. The distinction bias almost does not appear in the media content experience circumstance. The predicted utility sourced from online communications data and the experienced utility acquired by the episode's viewing is not notably different. We infer the reason about the little distinction bias in a TV streaming conditional situation is the availability of VOD (Video on Demand) or IPTV service. When people make predictions or choices, they are often in the joint evaluation (JE) mode; when people experience an event, they are often in the single evaluation (SE) mode. The availability of alternative content experience with VOD or IPTV service makes the condition of SE mode useless.

In a practical perspective, this study has a meaningful suggestion as a strategy that marketing promotion before the first broadcasting is the key to the success of the new TV series content. It is possible to influence the media consumers' behavior (choosing and consuming) from the first episode to the almost end part of the episodes. Media consumers have a tendency not to change their preference easily constructed by the early generated online communications data.

There are perceived several limitations to this study. First, for text mining, direct manual monitoring and classification work (if the comment is positive or negative/ if the comment has nothing to do with the TV shows) were done for higher accuracy among the complex and ambiguous expressions in the Korean language. Because of this time-consuming editing process, the number of TV series' titles is limitedly less than data collected by crawling bot. For increasing the sample content data (the quantity of TV series titles), we need accurate and sensitive mining software programs. The integrated theoretical framework and empirical findings above provided by the present study should serve as a good start for future research. 


\section{References}

[1] Tversky, A., \& Kahneman, D., "The Framing of Decisions and the Psychology of Choice," Environmental Impact Assessment, Technology Assessment, and Risk Analysis, pp. 107-129, 1985. Article (CrossRef Link).

[2] Van Exel, N. J. A., Brouwer, W. B. F., van den Berg, B., \& Koopmanschap, M. A., "With a little help from an anchor: discussion and evidence of anchoring effects in contingent valuation," The Journal of Socio-Economics, 35(5), 836-853, 2006. Article (CrossRef Link).

[3] Guo, M., \& Chan-Olmsted, S. M., "Predictors of social television viewing: How perceived program, media, and audience characteristics affect social engagement with television programming,” Journal of Broadcasting \& Electronic Media, 59(2), 240-258, 2015. Article (CrossRef Link).

[4] Chan-Olmsted, S. M., \& Park, J. S., "From on-air to online world: Examining the content and structures of broadcast TV stations' websites," Journalism \& Mass Communication Quarterly, 77(2), 321-339, 2000. Article (CrossRef Link).

[5] A. C., "What Americans do online: social media and games dominate activity," Nielsen, 2010. Article (CrossRef Link).

[6] Smith, A., \& Boyles, J. L., "The rise of the "connected viewer."," Pew Research Center's Internet and American Life Project, 2012. Article (CrossRef Link).

[7] Furnham, A., \& Boo, H. C., "A literature review of the anchoring effect," The Journal of Socio-Economics, 40(1), 35-42, 2011. Article (CrossRef Link).

[8] Goldhaber, M. H., "The attention economy and the net," First Monday, 2(4), 7 April 1997. Article (CrossRef Link).

[9] Owen, B. M., Beebe, J., \& Manning, W., “TV Economics,” DC Heath, London., 1974.

[10] Webb, G. K., "The economics of cable television,” Lexington, MA: Lexington Books., 1983.

[11] Owen, B. M., \& Wildman, S. S., "Video economics,” La Editorial, UPR, 1992.

[12] Picard, R. G., "Historical trends and patterns in media economics," Handbook of media management and economics, 23-36, 2006.

[13] Küng, L., "Does media management matter? Establishing the scope, rationale, and future research agenda for the discipline,” Journal of Media Business Studies, 4(1), 21-39, 2007. Article (CrossRef Link).

[14] Bucy, E. P., "Media credibility reconsidered: Synergy effects between on-air and online news," Journalism \& Mass Communication Quarterly, 80(2), 247-264, 2003. Article (CrossRef Link).

[15] "How chatter matters in TV viewing," CTAM, May 4, 2012. Article (CrossRef Link).

[16] Russell, C. A., Norman, A. T., \& Heckler, S. E., "The consumption of television programming: Development and validation of the connectedness scale," Journal of Consumer Research, 31(1), 150-161, 2004. Article (CrossRef Link).

[17] Gibs, J., \& Bruich, S., "Advertising effectiveness: Understanding the value of a social media impression,” New York, NY: The Nielsen Company, 2010.

[18] Wang, J. C., \& Chang, C. H., "How online social ties and product-related risks influence purchase intentions: A Facebook experiment," Electronic Commerce Research and Applications, 12(5), 337-346, 2013. Article (CrossRef Link). 
[19] McClellan, S., “'The Hills' Is Alive: MTV Research Links Cross-Platform Marketing to Brand Affinity among Web Users,"AdWeek, 2008.

[20] Ahn, J., Ma, K., Lee, O., \& Sura, S., "Do big data support TV viewing rate forecasting? A case study of a Korean TV drama,” Information Systems Frontiers, 19(2), 411-420, 2017. Article (CrossRef Link).

[21] Engel, A. K., König, P., Kreiter, A. K., \& Singer, W., "Interhemispheric synchronization of oscillatory neuronal responses in cat visual cortex,” Science, 252(5009), 1177-1179, 1991. Article (CrossRef Link).

[22] Shiloh, S., Salton, E., \& Sharabi, D., "Individual differences in rational and intuitive thinking styles as predictors of heuristic responses and framing effects," Personality and Individual Differences, 32(3), 415-429, 2002. Article (CrossRef Link).

[23] Ariely, D., Loewenstein, G., \& Prelec, D., ““'Coherent arbitrariness”: Stable demand curves without stable preferences,” The Quarterly Journal of Economics, 118(1), 73-106, 2003. Article (CrossRef Link).

[24] Mussweiler, T., Strack, F., \& Pfeiffer, T., "Overcoming the inevitable anchoring effect: Considering the opposite compensates for selective accessibility,” Personality and Social Psychology Bulletin, 26(9), 1142-1150, 2000. Article (CrossRef Link).

[25] Wansink, B., Kent, R. J., \& Hoch, S. J., "An anchoring and adjustment model of purchase quantity decisions,” Journal of Marketing Research, 35(1), 71-81, 1998.

Article (CrossRef Link).

[26] Blankenship, K. L., Wegener, D. T., Petty, R. E., Detweiler-Bedell, B., \& Macy, C. L., "Elaboration and consequences of anchored estimates: An attitudinal perspective on numerical anchoring,” Journal of Experimental Social Psychology, 44(6), 1465-1476, 2008. Article (CrossRef Link).

[27] Wegener, D. T., Petty, R. E., Detweiler-Bedell, B. T., \& Jarvis, W. B. G., "Implications of attitude change theories for numerical anchoring: Anchor plausibility and the limits of anchor effectiveness,” Journal of Experimental Social Psychology, 37(1), 62-69, 2001.

Article (CrossRef Link).

[28] Wegener, D. T., Petty, R. E., Blankenship, K. L., \& Detweiler-Bedell, B., “Elaboration and numerical anchoring: Implications of attitude theories for consumer judgment and decision making” Journal of Consumer Psychology, 20(1), 5-16. Article (CrossRef Link).

[29] Wilson, T. D., Houston, C. E., Etling, K. M., \& Brekke, N., "A new look at anchoring effects: basic anchoring and its antecedents,” Journal of Experimental Psychology: General, 125(4), 387-402, 1996. Article (CrossRef Link).

[30] Epley, N., \& Gilovich, T., "When effortful thinking influences judgmental anchoring: differential effects of forewarning and incentives on self-generated and externally provided anchors,” Journal of Behavioral Decision Making, 18(3), 199-212, 2005.

Article (CrossRef Link).

[31] Strack, F., \& Mussweiler, T., "Explaining the enigmatic anchoring effect: Mechanisms of selective accessibility,” Journal of personality and social psychology, 73(3), 437-446, 1997. Article (CrossRef Link).

[32] Frederick, S., "Automated choice heuristics," Heuristics and Biases: The Psychology of Intuitive Judgment. New York: Cambridge University Press, 548-558, 2002.

Article (CrossRef Link). 
[33] Hsee, C. K., \& Rottenstreich, Y., "Music, Pandas, and Muggers: On the Affective Psychology of Value," Working paper, Center for Decision Research, The University of Chicago Graduate School of Business, 1-37, 2002. Article (CrossRef Link).

[34] Kahneman, D., Schkade, D. A., \& Sunstein, D., "Shared Outrage and Erratic Awards: The Psychology of Punitive Damages,” Journal of Risk and Uncertainty, 16(1), 49-86, 1998. Article (CrossRef Link).

[35] Loewenstein, G. F., "Out of control: visceral influences on behavior," Organizational Behavior and Human Decision Processes, 65(3), 272-292, 1996. Article (CrossRef Link).

[36] Loewenstein, G. F., Weber, E. U., Hsee, C. K., \& Welch, N., "Risk as feelings,” Psychological Bulletin, 127(2), 267-286, 2001. Article (CrossRef Link).

[37] Rottenstreich, Y., \& Hsee, C. K., "Money, kisses, and electric shocks: On the affective psychology of risk," Psychological Science, 12(3), 185-190, 2001. Article (CrossRef Link).

[38] Slovic, P., Finucane, M., Peters, E., \& MacGregor, D. G., "Rational actors or rational fools: implications of the affect heuristic for behavioral economics," Journal of Socio-Economics, 31(4), 329-342, 2002. Article (CrossRef Link).

[39] Sunstein, C., Schkade, D. A., \& Kahneman, D., "Do People Want Optimal Deterrence?,” The Journal of Legal Studies, 29(1), 237-253, 2000. Article (CrossRef Link).

[40] Kahneman, D., Snell, J., "Predicting utility," Insights in Decision Making. University of Chicago, Chicago, 295-310, 1990. Article (CrossRef Link).

[41] Kahneman, D., Snell, J., "Predicting a changing taste," Journal of Behavioral Decision Making, 5(3), 187-200, 1992. Article (CrossRef Link).

[42] Kahneman, D., Wakker, P. P., \& Sarin, R., "Back to Bentham? Explorations of Experienced Utility,” The Quarterly Journal of Economics, 112(2), 375-406, 1997.

Article (CrossRef Link).

[43] Hsee, C. K. \& Zhang, J., "Distinction Bias: Misprediction and Mischoice Due to Joint Evaluation. Journal of Personality and Social Psychology, 86(5), 680-695, 2004.

Article (CrossRef Link).

[44] Van de Van, A. H., \& Ferry, D. L., "Measuring and assessing organization," New York: Wiley Inter-science, 1980. Article (CrossRef Link).

[45] Miles, J., “Tolerance and variance inflation factor,” Encyclopedia of statistics in behavioral science, 2005. Article (CrossRef Link).

[46] O’brien, R. M., “A caution regarding rules of thumb for variance inflation factors," Quality \& Quantity, 41(5), 673-690, 2007. Article (CrossRef Link). 


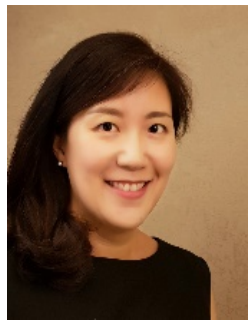

Alice Kyungran Ma is a doctoral student in Media \& Technology Management at Cologne University. She received the B.S. degree in the Industrial Engineering at Korea University and her M.S. degree in Information Systems at Hanyang University. She has great interest in media consumers' behavior for video content media using user generated big data with behavioral economics perspective and consumer psychology.

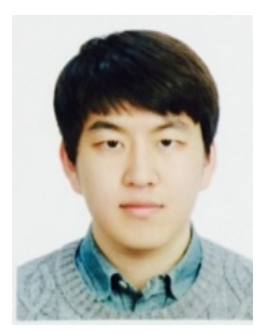

Takhun Kim has his master degree in the School of Management Engineering at KAIST. He received his B.S. degree in the Department of Chemical and Bio-molecular Engineering / Business and Technology Management at KAIST. He has his great interest in data-driven research in the school of Information Systems.

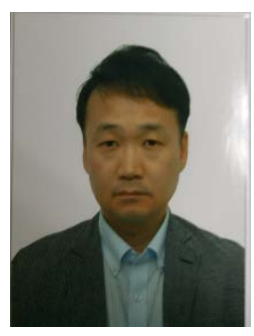

Jongchang Ahn is currently associate professor at the Department of Information Systems in Hanyang University. He received his B.S. degree in Economics at Korea University and his M.S. degree in Software Engineering from Sejong University. He received his $\mathrm{Ph}$. D. in Information Systems from Hanyang University. He has great interest in Knowledge Management, Social Media \& Mass Media, and IT Users' Behavior. 